\title{
Metamodeling of building energy consumption focused on climate, operation, space use and users related factors
}

\author{
Aymeric Novel $^{1,2^{*}}$, Francis Allard ${ }^{1}$, and Patrice Joubert ${ }^{1}$ \\ ${ }^{1}$ LaSIE, Université de La Rochelle, Av. Michel Crépeau, 17043 La Rochelle cedex 1, France \\ ${ }^{2}$ TERAO, 10 Cité de Trévise, 75009 Paris, France \\ *anovel@terao.fr
}

\begin{abstract}
Energy performance guarantee projects aim at achieving a given energy consumption in real life conditions. Building energy consumption monitoring during operation phase often reveals that energy consumption is sensitive to building spaces use and systems operation quality, especially for buildings with high energy performance characteristics [7]. Other investigations show the impact of building users' behaviour on energy consumption [28]. These factors must be added to climate factors for energy consumption prediction during operation phase. Number of factors and possible combinations is very high. Building energy modeling is limited regarding this issue and metamodeling has been used to solve this problem [25]. We developed metamodels that are polynomial functions using D-optimal design of experiment (DOE) approach. Such metamodels can become operational tools to use in the IPMVP framework, associated with a M\&V plan. This paper shows the application of the method on a cultural building that comprises numerous systems and usages. We obtain a reliable metamodel of the energy consumption as a function of climate, operation, and space use factors. which meets IPMVP [11] and ASHRAE Guideline 14 [3] modeling uncertainties criteria. We also determine the global uncertainty resulting from predictors' uncertainties propagation and modelling uncertainty associated with the metamodel.
\end{abstract}

\section{Introduction}

The building sector is one of the largest greenhouse gas emission emitters at the global scale. Therefore, building sector energy demand reduction is critical. In France, the national building energy code, named "RT", has been implemented and have become gradually more stringent, allowing for the improvement of building envelope and HVAC systems energy performance. However, the RT code evaluates a theoretical energy performance only. Moreover, this evaluation includes only a fraction of total energy end-uses. Since building envelope and HVAC systems characteristics regularly improve, the weight of non-regulatory energy end-uses increases. These energy end-uses are typically associated with building users' activities. In addition, high performance buildings show new issues related to HVAC systems operations and impact of users' behaviour ([7], [28]). Because of these trends, associated with the on-going increase of the building stock size, the actual energy consumption of the building sector in France has not decreased so much ([1], [16]). Energy consumption during operation phase often exceeds design phase's calculated energy consumption target [22]. Energy performance guarantee is an efficient tool to manage real life energy consumption. It aims at achieving real-life energy consumption target. It is used to quantify and manage the risk associated with energy consumption deviation. Modeling these risks is done with the baseline adjustment method. Adjustment is typically considered for heating/cooling degree-days. Adjustment models solely based on degree-days provide easy and fast calculations but are not accurate enough and do not consider other factors that may be important [18]. Energy performance guarantee may be limited in cases where a building's use changes have a too strong impact on energy consumptions, meaning when adjustments cause such variations that the energy performance contract relevance and economical balance are compromised. According to the author, this is a current limit to energy management since dedicated risk management tool cannot address such situation. In general, the factors that impact energy consumption belong to the following categories: climate, envelope, activities (occupancy, process), lighting, HVAC controls, water pipes and air ducts length, fresh air treatment, terminal units, domestic hot water (DHW), production and distribution efficiencies [20]. Some of these categories are addressed during design and construction phases. Others are operation phase variables: climate, activities (occupancy and process), lighting and HVAC controls. Building energy performance simulation (BEPS) can be used to calculate the impact of these factors on energy consumption. However, the number of factors and possible combinations is high. Using BEPS would require thousands of simulations to carry out sensitivity

\footnotetext{
$\overline{{ }^{*} \text { Corresponding author: author@e-mail.org }}$
} 
analysis and uncertainties propagation, which is an obstacle ([6], [23]). Metamodeling has been used to address this issue since metamodels can be a good compromise between accuracy and calculation speed [17]. Design of experiment (DOE) approach has been used to create metamodels ([6], [18], [25]). Among the available design of experiment approaches, D-optimal DOE are adapted to create polynomial functions that predict building energy consumption [25]. We propose a two-step method. Firstly, we developed polynomial energy models that can predict energy consumption as a function of building's activities characteristics and HVAC systems operations factors. To achieve this, we used EnergyPlus software in order to build reliable energy models along with the design of experiments method (DOE) to build a metamodel associated with a modeling error. In parallel, we analyzed several feedbacks to build a database of building operation phase factors that are potential energy consumption predictors. We also defined how to determine the appropriate structure of the polynomial model to reach a good compromise between model accuracy and calculation time. Secondly, we used measurement and verification $(\mathrm{M} \& \mathrm{~V})$ data, associated with probability functions, to determine the associated uncertainty of the calculated energy consumption. Finally, we combine the latter with the polynomial modeling error to calculate the energy consumption global uncertainty, with the goal to identify strategies to reduce it.

\section{Methodology}

The methodology we have developed aimed at reducing calculation time, identifying significant predictors, linking the model's structure and the M\&V plan and being able to propagate predictors' value uncertainties through the model.

\subsection{Global uncertainty calculation}

The goal is to reduce the global uncertainty on energy consumption during operation phase. Global uncertainty is defined as the sum of modelling, measurement and sampling uncertainties [11], and is expressed by the following equation [12]:

$$
S E=\sqrt{S E(\text { modeling })^{2}+S E(\text { measure })^{2}}
$$

Where SE is the global standard error, $\mathrm{SE}$ (modeling) is the modeling standard error and $\mathrm{SE}$ (measurement) is the measurement standard error. Modeling error is well defined in the literature, using the root mean square error (RMSE), the mean bias error MBE and their coefficients of variation, expressed by:

$$
\begin{aligned}
& R M S E=\sqrt{\frac{\sum\left(\widehat{Y}_{l}-Y_{i}\right)^{2}}{n-P-1}} \\
& C V(R M S E)=\frac{R M S E}{\bar{Y}}
\end{aligned}
$$

$$
\begin{gathered}
M B E=\frac{\sum\left(\hat{Y}_{i}-Y_{i}\right)}{n-p} \\
N M B E=\frac{M B E}{\bar{Y}}
\end{gathered}
$$

IPMVP [11] and ASHRAE [3] provides values to be used for energy model evaluation:

Table 1. Reference values for CV(RMSE) and NMBE.

\begin{tabular}{|c|c|c|}
\hline Source & CV(RMSE) & NMBE \\
\hline ASHRAE-14 & $15 \%$ & $5 \%$ \\
\hline IPMVP & $15 \%$ & $7.5 \%$ \\
\hline
\end{tabular}

ASHRAE Guideline 14 provides a more detailed formula, which we express in a simplified form as follow:

$$
\begin{gathered}
S E= \\
\sqrt{\frac{C V(R M S E)^{2}}{m} \times 5,12 \times n+U_{s}^{2}+R E_{\text {instrument }}^{2}+U_{i v}^{2}}
\end{gathered}
$$

Where CV(RMSE) corresponds to the baseline model, $n$ is the number of baseline observation points, $m$ is the number of $M \& V$ period observation points, $U_{s}$ is the measurement sampling error, $\mathrm{RE}_{\text {instrument }}$ is the measurement instrument error and $U_{\text {iv }}$ is the error of the model energy consumption calculation due to the sampling and measurement errors on predictors. It is possible to define probability distribution for each predictor in relation to measurement and sampling errors during the $\mathrm{M} \& \mathrm{~V}$ period. Moreover, with nowadays computing capacities, it is possible to do probabilistic simulations. By sampling randomly values from the distributions associated with each predictor, we can calculate the probability distribution of the energy consumption determined by the adjustment model. Such distribution can be associated with a standard error, which we name SE(propagation). Based on this principle, we have defined global uncertainty as follow:

$$
\frac{S E=}{\sqrt{S E(\text { modeling })^{2}+S E(\text { propagation })^{2}}}
$$

\subsection{Metamodel selection}

In common $\mathrm{M} \& \mathrm{~V}$ practices, in the context of options $\mathrm{A}$ $\mathrm{B}$ and $\mathrm{C}$ as defined by IPMVP, energy models used for adjustment are linear. These models are built from metered data during the baseline period with multilinear regression approach. When using option $\mathrm{D}$, numerical models can also be used using simulations software. Building metamodels from simulation software can be seen as a third way to obtain an energy model to be used for $\mathrm{M} \& \mathrm{~V}$. There is a variety of metamodels and multilinear functions are only one type, which may be too simple and only valid locally in some cases. Other types of metamodels include polynomial regression, multivariate adaptative regression splines (MARS), gaussian process regression (GPR), artificial neural 
network (ANN), support vector regression (SVR), classification and regression trees (CART) and random forest (RF). They have been used for multicriteria design optimization ([18], [25]), regression on metered data ([4], [8]), model calibration on existing building ([6], [20]), thermal and visual comfort [5] and complex systems thermal behavior ([9], [14]). In terms of scale, they have been used from building zone level to HVAC system [31], whole building ([19], [25]), campus ([27], [32]), city [24], building sector level [13] and country level [21]. In terms of time step, they have been used for hourly ([8], [15], [30]), daily [8], monthly and yearly calculations [25]. Several authors have analyzed the benefits and inconvenient of all these metamodels for building energy consumption calculation application ([27], [32], [23]). To summarize, these authors show that multilinear or polynomial regression approaches still provide a good balance between accuracy, ease of use and transparency compared to more sophisticated approached that can also be called "black-box". These methods may give more accurate results in some cases but they require an advanced expertise level and require more time to implement. They are recommended for specific applications or situations where data is lacking. We summarize the comparison in table 2. Among the models that can be obtained from regression approach, we have considered quadratic polynomial functions:

$$
y=a_{0}+\sum a_{i} x_{i}+\sum a_{i j} x_{i} x_{j}+\sum a_{i i} x_{i}^{2}
$$

Such polynomial functions have been successfully used either to approximate building energy modeling results for heating and cooling loads during design phase [25] or to build statistical model with metered data to estimate the effect of global warming on energy consumption [29].

Table 2. Synthetic comparison between regression and other metamodels approaches.

\begin{tabular}{|c|c|c|}
\hline & $\begin{array}{l}\text { "black-box" } \\
\text { metamodels }\end{array}$ & $\begin{array}{l}\text { Regression-based } \\
\text { metamodels }\end{array}$ \\
\hline Example & ANN & $\begin{array}{c}\text { polynomial } \\
\text { regression }\end{array}$ \\
\hline Application & $\begin{array}{c}\text { Short timestep, } \\
\text { predictive control } \\
\text { for smart grids or } \\
\text { TABS }\end{array}$ & $\begin{array}{l}\text { Long timestep, } \\
\text { monthly energy use } \\
\text { prediction }\end{array}$ \\
\hline $\mathrm{M} \& \mathrm{~V}$ & Lack of data & $\begin{array}{c}\text { Sufficient amount of } \\
\text { data }\end{array}$ \\
\hline
\end{tabular}

To build the metamodel from simulation, one must generate a learning database. Design of experiment (DOE) optimize the number of combinations of values to generate the sample. Random sampling and LHS cover better the range of possible values of predictors but they require more calculation time. Several studies show that design of experiments can be successfully used to create reliable polynomial functions ([6], [18], [25]). Design of experiment allow us identifying the significant predictors as well as interactive effects, with statistical tests such as $\mathrm{p}$-value (qualitative) and with regression coefficients (quantitative). Especially, D-optimal DOE are interesting because they aim at optimizing the number of points for a better accuracy by changing the value of all descriptors for each set of data. Such result is achieved by meeting the D-optimality criterion. To carry out this calculation, each factor must be expressed as a dimensionless value $\mathrm{X}$ defined by:

$$
X=\frac{x-x_{0}}{p}
$$

With $\mathrm{X}$ between -1 and +1 , $\mathrm{x}$ a physical value between $\mathrm{x}_{\min }$ and $\mathrm{x}_{\max }, \mathrm{x}_{0}$ the central value of the domain $\left[\mathrm{x}_{\min } ; \mathrm{x}_{\max }\right]$ and $\mathrm{p}$ the variation step, respectively defined by:

$$
\begin{gathered}
x_{0}=\frac{x_{\max }+x_{\min }}{2} \\
p=\frac{x_{\max }-x_{\min }}{2}
\end{gathered}
$$

The D-optimum dimensionless experiment matrix E corresponds to the one that maximizes the matrix determinant E'E.

\subsection{Descriptors definition}

We have analyzed a number of field reports ([2], [7], [10], [26]) as well as the literature ([20], [33]) to obtain a comprehensive mapping of the relevant descriptors of energy consumption during operation phase. We have classified the descriptors in four categories: climate (temperature, absolute or relative humidity, solar irradiation), space use and process (occupancy types, rates and schedule, process energy use), users' behavior (openings and blinds use, DHW volumes, computer idle mode use...), HVAC systems operation (temperature and flow rates setpoints, maintenance, regulation). We have considered that it is possible to define indicators for each category based on representative averages for each calculation timestep, in a very similar way that degreedays are used to follow-up a more or less cold weather monthly. Table 3 illustrates this approach:

Table 3. Descriptors of energy use during operation phase.

\begin{tabular}{|c|c|c|}
\hline $\begin{array}{c}\text { Descriptor } \\
\text { category }\end{array}$ & $\begin{array}{c}\text { Principle to follow- } \\
\text { up }\end{array}$ & $\begin{array}{c}\text { Example of } \\
\text { indicators }\end{array}$ \\
\hline Climate & Climate rigor & Heating degree-days \\
\hline Behaviour & Users' awareness & $\begin{array}{c}\text { Monthly average of } \\
\text { daily windows } \\
\text { opening duration }\end{array}$ \\
\hline $\begin{array}{c}\text { Space use } \\
\text { and process }\end{array}$ & $\begin{array}{c}\text { Space use energy } \\
\text { intensity }\end{array}$ & $\begin{array}{c}\text { Monthly average of } \\
\text { daily process } \\
\text { equipment power }\end{array}$ \\
\hline $\begin{array}{c}\text { HVAC } \\
\text { operation }\end{array}$ & Indoor air quality & $\begin{array}{c}\text { Monthly average of } \\
\text { daily outdoor } \\
\text { airflow rate }\end{array}$ \\
\hline
\end{tabular}


Using this type of definition and having analyzed which descriptors are relevant to predict energy use during operation phase allow for the definition of the $M \& V$ plan.

\subsection{Overall methodology}

In practice, metamodel and $\mathrm{M} \& \mathrm{~V}$ plan development should be done in parallel to ensure relevant data are measured consistently with the model and that the global uncertainty good enough to demonstrate proper energy management during operation phase. Figure 1 illustrates the overall methodology.

\section{Case study}

We have applied this methodology on a $11000 \mathrm{~m}^{2}$ cultural building, located in Paris built in 2015. This case study has been chosen because it is representative of the issue we have identified: its space use is highly variable because it is related to event programs and there is great diversity of spaces. Moreover, HVAC systems operations have multiple constraints that are exhibitions' artworks security oriented. This means that energy performance is not the priority and finding ways to save energy requires accurate understanding of systems operation. We have worked on this building case study since the design phase and have followed-up its performance during operation. With regards to modeling, we have begun by building an energy model on EnergyPlus based on as-built documentation and site visit. The first purpose of this model was to provide an energy performance evaluation for the French green building rating system HQE. Then, we have applied IPMVP option D methodology for energy performance follow-up. The energy model has been adjusted to match data that were measured during 11 months. In parallel, $\mathrm{M} \& \mathrm{~V}$ data were analyzed to understand the site's activities and HVAC systems operation. Based on this work and our operation phase descriptors database, we identified relevant descriptors to build a metamodel with the design of experiment method. The metamodel was tested against the energy model and allowed us to rank descriptors in terms of weight on energy consumption. We analyzed and made assumptions about M\&V data accuracy and associated probability distributions. Lastly, we could propagate these uncertainties through the metamodel and obtain a global uncertainty in order to determine how to reduce it.

\subsection{Presentation of the case study}

The studied building has "three" skins: exterior shadings that are part of the architectural concept and form an opened assembly though it is large enough to shade most of the building, a closed enveloped called "iceberg volumes" which is composed of Ductal ${ }^{\circledR}$ concrete with $17 \mathrm{~cm}$ insulation $\left(\mathrm{U}=0.27 \mathrm{~W} / \mathrm{m}^{2} . \mathrm{K}\right)$ and ventilated volume maintained at $14^{\circ} \mathrm{C}$ by heat recovery dedicated AHUs, and insulated walls $\left(\mathrm{U}=0.33 \mathrm{~W} / \mathrm{m}^{2} . \mathrm{K}\right)$ that are in contact with heated/cooled interior spaces. Vertical and horizontal glazing have a Ucw of $1.7 \mathrm{~W} / \mathrm{m}^{2} . \mathrm{K}$. SHGC is $43 \%$ and $16 \%$ for vertical and horizontal glazed area respectively. Thermal zoning has been done in order to calculate realistic heating and cooling loads and total energy consumption. Overall, we followed the thermal zoning methodology described in figure 2.

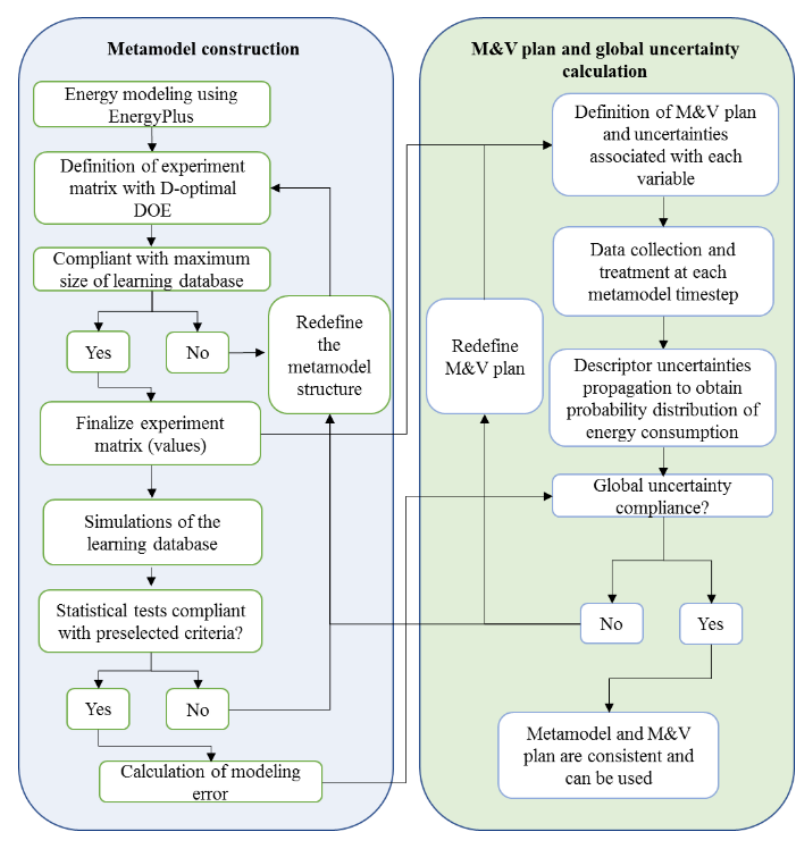

Fig. 1. Overall schematic methodology.

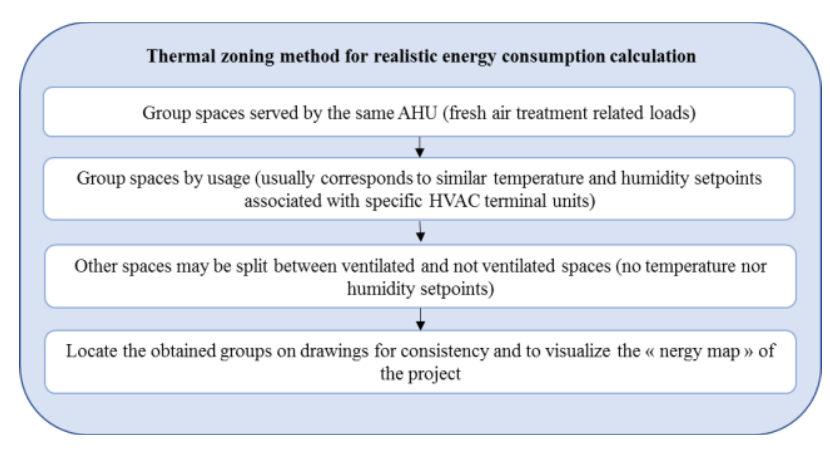

Fig. 2. Thermal zoning methodology.

Zones include the following types: exhibition galleries, office spaces, library, auditorium, lobby, VIP room, restaurant and kitchen, storage and various auxiliary spaces. Indoor climate control is summarized in table 4 . Heating and cooling plant consist in two thermo refrigerating pump (TFP), providing simultaneously hot and chilled water all year round. In heating mode, each machine can deliver $757 \mathrm{~kW}$ of heating capacity and reject $550 \mathrm{~kW}$ of cooling capacity that can be recovered. In cooling mode, each machine can deliver $650 \mathrm{~kW}$ of cooling capacity and reject $777 \mathrm{~kW}$ of cooling capacity can be recovered. 
Table 4. Indoor climate control strategies.

\begin{tabular}{|c|c|}
\hline Zone type & HVAC systems type \\
\hline Exhibition & VAV + radiant floors \\
\hline Office type & CAV + fan coils \\
\hline Other spaces & VAV \\
\hline Kitchen & VAV + exhaust hoods \\
\hline
\end{tabular}

\subsection{Highlights about the site's operation and activities and assumptions}

In this section we describe the findings about site's activities we made for energy model adjustment. Some information is derived from metered data, some is derived from interviews and spot check, some is assumed and has been one plausible solution for energy model adjustment.

Exhibition galleries are tightly conditioned all year round, night and day. When there is lots of visitors, some galleries are exposed to uncontrolled outdoor airflows that add to the thermal loads. The average equipment and lighting power density in the galleries is $35 \mathrm{~W} / \mathrm{m}^{2}$. they are opened $10 \mathrm{~h} /$ day but the base lighting is turned on longer, from 6am due to cleaning works. Each gallery has its own AHU with a specific fresh air damper position obtained after system balancing procedure but which was never changed after. The average damper position is $38 \%$. The average supply fan is at $59 \%$ of its design frequency. The average supply air temperature is $22.8^{\circ} \mathrm{C}$. For all zones that are not exhibition space or the kitchen of the restaurant, average equipment and lighting power density is $14.5 \mathrm{~W} / \mathrm{m}^{2}$, used during $10 \mathrm{~h} 30 /$ day. Average supply air temperature is $23^{\circ} \mathrm{C}$ and average return air temperature is $22.4^{\circ} \mathrm{C}$. The average fresh air damper position is at $74 \%$, knowing that some of the AHUs are DOAS type. For kitchen area, we had to make assumption from a similar site, as it was separated from the rest of the project in terms of management, but not for energy supply and management. Average electrical power was taken at $450 \mathrm{~W} / \mathrm{m}^{2}$ with $80 \mathrm{~W} / \mathrm{m}^{2}$ associated heat gains. This is associated with full restaurant capacity (150 persons). We have linked this consumption to the restaurant actual occupancy rate with a $30 \%$ fixed minimum consumption. It was found that the restaurant has a $80 \%$ occupancy rate in average. Lighting power density was taken at $15 \mathrm{~W} / \mathrm{m}^{2}$. The VAV AHU design supply airflow rate is taken at 20 ach with supply air temperature between 20 and $25^{\circ} \mathrm{C}$. According to the site's statistics, 2800 persons/day come during weekdays, and 3500 persons/day come during weekends in average. The site is opened to visitors $10 \mathrm{~h} /$ day six days per week. We have assumed an even distribution of the visitors over the accessible areas and an average metabolic rate of $140 \mathrm{~W} /$ person. Specific visitors flow to the auditorium has been more difficult to estimate and we obtained a value of 225 person per event in average, once a week during $4 \mathrm{~h}$. In addition, process energy use were identified including fountains $(42 \mathrm{~kW})$, one exterior lighting artwork (24kW), exhaust fans used permanently
(30kW), exterior lighting $(45 \mathrm{~kW})$, escalators $(37 \mathrm{~kW})$ and pumps associated to plumbing (14kW).

\subsection{Baseline energy model results}

Figure 3 illustrates the energy use breakdown of the site as calculated by the baseline energy model:

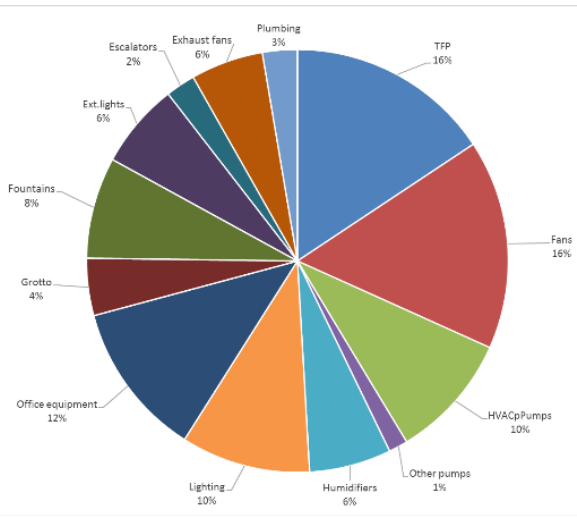

Fig. 3. Energy use breakdown

Relative difference between energy bills and modelled consumption over the monitored period, from June 2015 to April 2016 varies from 1\% to $13 \%$. From this, we could calculate the RMSE of this model at $30098 \mathrm{kWh} /$ month, giving a CV(RMSE) of $7.6 \%$. Considering 11 points of observation and $95 \%$ confidence level, we can use the t-statistic at 2.26 to define a modelling uncertainty of $+/-68020 \mathrm{kWh} /$ month, or $+/-17.3 \%$. When using this statistic, we can see that later energy bills (2016 and 2017) fall within this range as shown on figure 4 .

\subsection{Metamodel development}

The initial phase of energy model adjustment and site's operation analysis allow us having a base model that is representative of the site's energy use, although it is not a calibration but only one plausible solution among others. Figure 5 illustrates the methodology we have developed to determine the proper structure of the metamodel. To determine the proper timestep, we have found that the average duration of exhibitions was 4 months and that the duration of heating and cooling mode of the thermo refrigerating pumps was 6 months each. Therefore, to be consistent with the site's usage variations we could have chosen a quarterly timestep. However, considering that we had only 11 months of $\mathrm{M} \& \mathrm{~V}$ data we chose a monthly time step to have more observation points. With regards to the spatial step, we iterated several times to optimize the DOE sample size. Indeed, the more refined the spatial step is, the more descriptors we have and the larger the sample size will be. We found that it was optimum to define exhibition, non-exhibition and kitchen. Lastly, we grouped all lighting and equipment as one factor for each spatial 
group, and almost all factors were defined as $24 \mathrm{~h}$ daily average values. Only internal heat gains daily average were associated with occupied/unoccupied period because we considered the daily duration of equipment's use is a relevant descriptor.

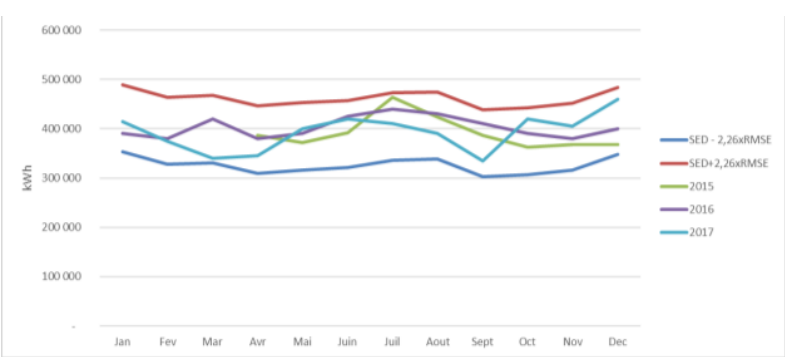

Fig. 4. Energy bills VS energy modelling uncertainty range.

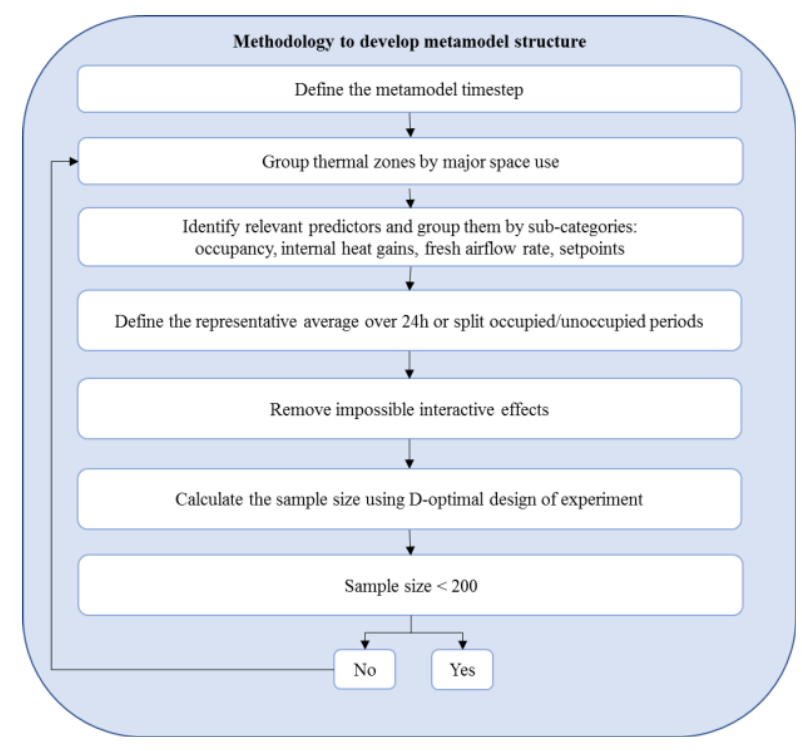

Fig. 5. Methodology to determine metamodel structure.

We assumed a partially quadratic model to build the learning database with D-optimal design of experiment theory:

$$
y=a_{0}+\sum a_{i} x_{i}+\sum a_{i j} x_{i} x_{j}
$$

Table 5 summarizes the sample size optimization, reducing the number of descriptors from 63 to 22 :

Table 5. DOE sample size optimization process.

\begin{tabular}{|c|c|}
\hline $\begin{array}{c}\text { Matrix of experiment and main } \\
\text { assumptions }\end{array}$ & $\begin{array}{c}\text { Sample } \\
\text { size }\end{array}$ \\
\hline $\begin{array}{c}\text { Spatial step: exhibition, office, auditorium, } \\
\text { kitchen, others }\end{array}$ & 2024 \\
\hline $\begin{array}{c}\text { Spatial step: exhibition, non-exhibition, } \\
\text { kitchen }\end{array}$ & 568 \\
\hline $\begin{array}{c}\text { Descriptors grouped by sub-categories and } \\
\text { averaged over 24h }\end{array}$ & 284 \\
\hline Impossible interactive effects removed & 180 \\
\hline
\end{tabular}

Descriptors for exhibition zones include: indoor air temperature setpoint (Gal_Tc), humification (Gal_Hc_min) and dehumidification (Gal_Hc_max) setpoints, equipment/lighting power density (Gal_Elec) and daily duration of use (Gal_Elec_Heures), percentage of fresh air supplied by AHUs (Gal AN), percentage of design supply air flow rate (Gal_AS), Supply air temperature (Gal_Tsouf) and AHU preheat temperature setpoint (Gal_Tprech). For non-exhibition zones, descriptors include equipment/lighting power density (NoGal_Elec) and daily duration of use (NoGal_Elec_Heures), indoor air temperature setpoint (NoGal_Tc), Supply air temperature (NoGal_Tsouf), percentage of fresh air supplied by AHUs (NoGal_AN), auditorium occupancy count (For_Occ) and schedule (For_Occ_Heures). For kitchen area, descriptor only include restaurant occupancy rate (Cui_Couv). Building level descriptors include degree-days (DJUc18, DJUf10), outdoor absolute humidity (HS moy), solar global horizontal irradiation (Sol moy), total visitors per day (Visit_Jour) and opening hours (Visit_Heures).

\subsection{Results}

For each month, we used the p-value test in order to identify the descriptors that had an effect on the energy consumption. We considered a threshold of 0.01 for the p-value. Table 6 shows the significant descriptors for summer months and Table 7 for winter months.

Table 6. Summer significant descriptors.

\begin{tabular}{|c|c|c|}
\hline Months & $\begin{array}{l}\text { Number of } \\
\text { significant } \\
\text { descriptors }\end{array}$ & $\begin{array}{c}\text { Common significant } \\
\text { descriptors }\end{array}$ \\
\hline May & 17 & \multirow{6}{*}{$\begin{array}{c}\text { Gal_AS, } \\
\text { Gal_Elec_Gal_Elec_Heures, } \\
\text { NoGal_Elec, } \\
\text { NoGal_Elec_Heures, } \\
\text { Gal_Hcmax, Hsmoy, DJUf10 }\end{array}$} \\
\hline June & 14 & \\
\hline July & 10 & \\
\hline August & 8 & \\
\hline September & 20 & \\
\hline October & 22 & \\
\hline
\end{tabular}

Table 7. Winter significant descriptors.

\begin{tabular}{|c|c|c|}
\hline Months & $\begin{array}{l}\text { Number of } \\
\text { significant } \\
\text { descriptors }\end{array}$ & $\begin{array}{c}\text { Common significant } \\
\text { descriptors }\end{array}$ \\
\hline November & 13 & \multirow{6}{*}{$\begin{array}{c}\text { Gal_AS, } \\
\text { Gal_Elec_Gal_Elec_Heures, } \\
\text { NoGal_Elec, } \\
\text { NoGal_Elec_Heures, } \\
\text { Gal_Hcmin, Hsmoy, DJUc18, } \\
\text { GalTprech, Gal_Tc, } \\
\text { NoGal_Tc, Gal_AN, } \\
\text { Cui Couv }\end{array}$} \\
\hline December & 18 & \\
\hline January & 14 & \\
\hline February & 17 & \\
\hline March & 17 & \\
\hline April & 15 & \\
\hline
\end{tabular}

We then applied least square optimization regression to determine the monthly polynomial functions. We show below the example for total energy consumption in June. We have added the 4 processes energy use to the polynomial function obtained: 


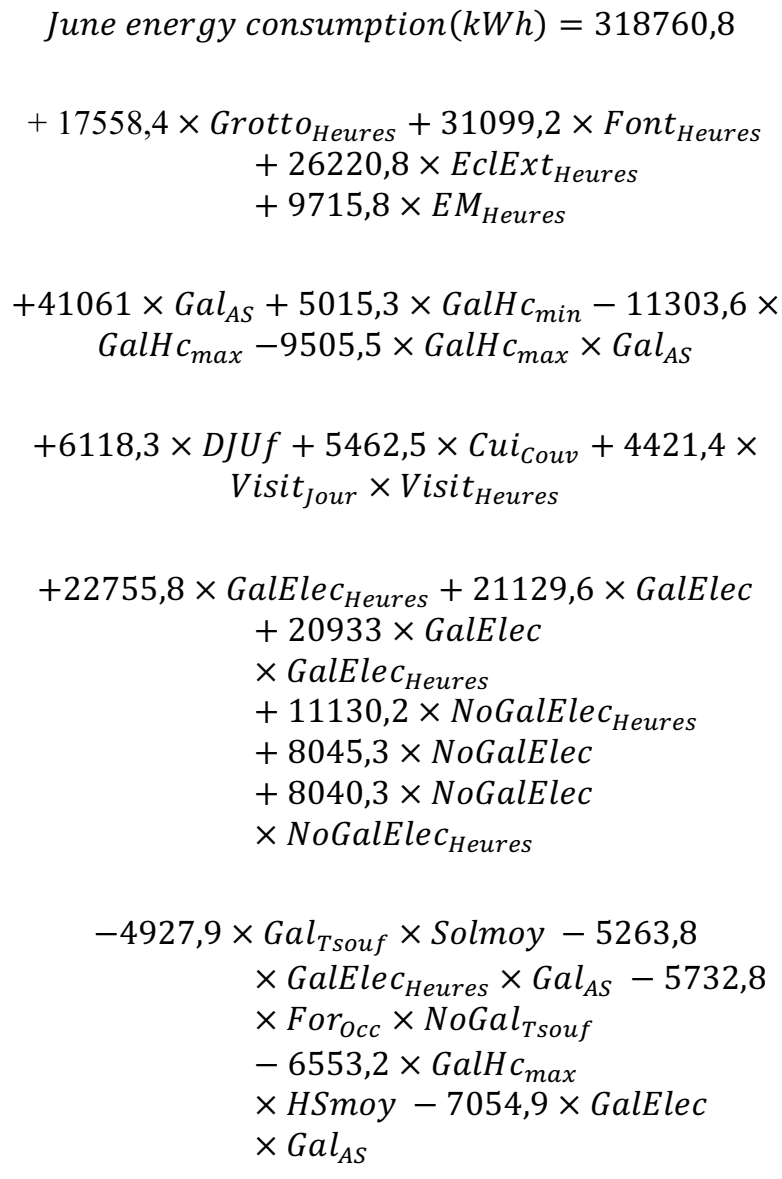

We can see that this polynomial function is composed by a constant term, process energy terms, exhibition HVAC operation terms, climate and visitors' terms, internal heat gains terms and a last group of interactive effects between climate, internal gains and HVAC operations descriptors. The statistical results used to compare the energy consumption calculated by the polynomial function against the EnergyPlus model showed that $\mathrm{R}^{2}$ coefficients are all at 0.99 , NMBE are all close to zero, and $\mathrm{CV}(\mathrm{RMSE})$ are all between $1.8 \%$ and $3.4 \%$. These results are acceptable according to IPMVP and ASHRAE criteria for statistical models. Based on the learning dataset defined by the DOE, we considered that modeling error is acceptable and used the developed monthly polynomial functions to propagate uncertainties about descriptors actual values during the $M \& V$ period. Available metered data were more focused on HVAC operation control and artwork security than energy performance. As a result, some of the descriptors that were identified as significant were not measured and large uncertainties about their actual values were then considered. Tables 8 summarize the probability distribution we considered for each descriptor in January 2016, for measured variables. Non-measured variables are associated with uniform distribution and large range of possible values.

We could carry out 50000 calculations with the polynomial functions using random samples of descriptors values, for each month. Figure 6 illustrates the calculated monthly energy consumption distribution for December.

Table 8. Normal distribution for measured desccriptors.

\begin{tabular}{|c|c|c|}
\hline Descriptor & Min value & Max value \\
\hline Gal_Tc & $19.9^{\circ} \mathrm{C}$ & $21.9^{\circ} \mathrm{C}$ \\
\hline Gal_Hc_min & $5.6 \mathrm{~g} / \mathrm{kg}_{\mathrm{da}}$ & $6.2 \mathrm{~g} / \mathrm{kg}_{\mathrm{da}}$ \\
\hline Gal_Hc_max & $7.9 \mathrm{~g} / \mathrm{kg}_{\mathrm{da}}$ & $8.7 \mathrm{~g} / \mathrm{kg}_{\mathrm{da}}$ \\
\hline Gal_AN & $42 \%$ & $51 \%$ \\
\hline Gal_AS & $51 \%$ & $62 \%$ \\
\hline Gal_Tsouf & $21.6^{\circ} \mathrm{C}$ & $23.6^{\circ} \mathrm{C}$ \\
\hline NoGal_Tc & $20.6^{\circ} \mathrm{C}$ & $22.6^{\circ} \mathrm{C}$ \\
\hline NoGal_Tsouf & $24.8^{\circ} \mathrm{C}$ & $26.8^{\circ} \mathrm{C}$ \\
\hline NoGal_AN & $28 \%$ & $46 \%$ \\
\hline Visit_jour & Exact value from Owner \\
\hline Visit_heures & $8 \mathrm{~h}$ & $12 \mathrm{~h}$ \\
\hline DJU & $+4.4^{\circ} \mathrm{C}$ & $+6.4^{\circ} \mathrm{C}$ \\
\hline
\end{tabular}

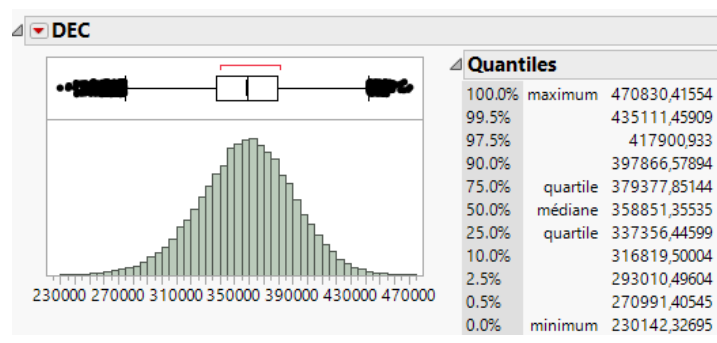

Fig. 6. Energy consumption distribution for December after descriptors uncertainties propagation.

Due to the unmeasured descriptors, the spread of the possible energy consumption values is large although there is a clear mean value of this classic bell-shaped curve. Figure 7 shows the comparison between the mean value of the calculated energy consumption values distribution and the actual energy bills during this period of time. We can see that there is a good match. The relative difference never exceeds $10 \%$ and it is $4.5 \%$ for the total over 11 months, which is a good result.

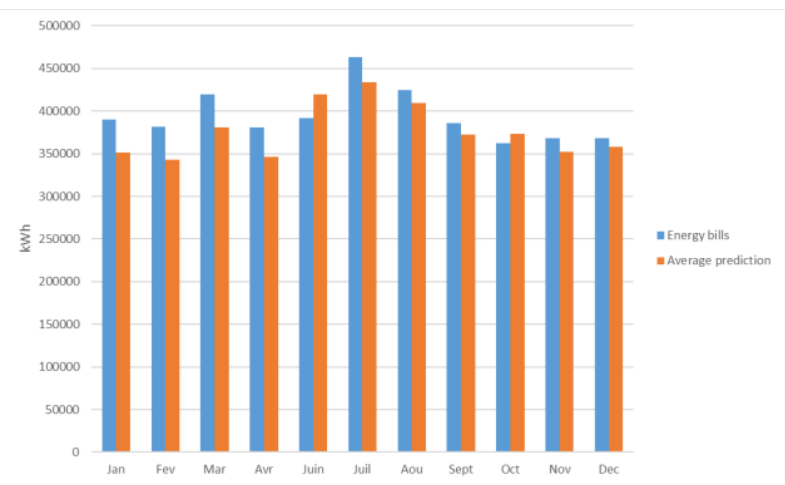

Fig. 7. Comparison between mean predicted (right column) and real energy consumption (left column).

Modeling uncertainty is between $5.6 \%$ and $8.8 \%$, propagation uncertainty is between $13.4 \%$ and $24.9 \%$ and global uncertainty is between $15 \%$ and $25 \%$. We can 
see that the uncertainty related to the lack of information on non-measured descriptors exceeds the modelling related uncertainty. Therefore, the first step to reducing global uncertainty is to improve the $\mathrm{M} \& \mathrm{~V}$ plan, and especially the equipment and lighting average power and use schedule.

\section{Conclusions}

The method was applied to a cultural building, which is in operations. We built a polynomial model for monthly total energy consumption as a function of factors such as the number of visitors, the minimum humidity levels setpoints of exhibitions' specific equipment power density. Modeling error is always less than $10 \%$ compared to the EnergyPlus model. We then used available monitored data over a period of 11 months, associated with their uncertainties, to estimate the total energy consumption and compare with real energy bills. Results show a difference of less than $10 \%$ between the average value of the predicted energy consumption and the real energy consumption for each month. The global uncertainty of the estimate is between $15 \%$ and $25 \%$, with the largest fraction due to the uncertainties related to input data. The results show that this method is adapted to model and monitor energy consumption in relation to building use and HVAC systems operations factors. Operation phase factors can be expressed as daily averages, similarly to heating or cooling degreedays and the structure of the polynomial models can easily be related to the M\&V plan. This method can therefore help to better manage energy consumption during operation phase.

\section{References}

1. ADEME, Chiffres clés 2015.

2. AQC, 2014. Retours d'expériences (REX), bâtiments performants \& risques. Version 3 Octobre 2014. ISBN : 978-2-35443-329-1.

3. ASHRAE Guideline 14 - 2002, measurement of energy, demand and water savings.

4. M.R.Braun, H.Altan, S.B.M.Beck, App. En. 130 (2014) 305-313.

5. B.Cao, Q.Ouyang, Y.Zhu, L.Huang, H.Hu, G.Deng, Build.Env.47(2012)394-399

6. A.Caucheteux, A.Gautier, R.Lahrech, 2016. Int. J. Metrol. Qual. Eng. 7, 402 (2016).

7. CEREMA, 2017. ISBN 978-2-37180-262-9.

8. W. Chung, Y.V.Hui, Y.M.Lam, App. En. 83 (2006) $1-14$.

9. J.J.C.Diaz, P.J.Garcia-Neto, F.P.Alvarez-Rabanal, M.Alonso-Martinez, J.Dominguez-Hernandez, J.M.Perez-Bella, Con.Build.Mat.52(2014)331-334.

10. Enertech, 2012. OPAC 74/Epagny (74), ZAC du Fort (Bron).

11. EVO, IPMVP Vol. I, 2012.
12. EVO, Uncertainty assessment for IPMVP, 10100$1: 2018$.

13. N.Fumo, M.A.Rafe Biswas, Ren. Sust. En.Rev. 47 (2015) 332-343.

14. D.Gossard, B.Lartigue, Ap Therm. Eng. 54(2013)549-558

15. Y.Heo, V.M.Zavala, En.Build. 53 (2012) 7-18.

16. INSEE, 2017. Le parc de logements en France au 1er janvier 2017.

17. B. Iooss, Journal de la Société Française de Statistique, 2011, 152 (1), pp.1-23.

18. I.Jaffal, C.Inard, En.Build. 151 (2017) 501-510.

19. J.C.Lam, K.K.W.Wan, D.Liu, C.L.Tsang, En.Con.Man. 51 (12) (2010) 2692-2697.

20. M.Manfren, N.Aste, R.Moshkar, 2013. App.En. 103 (2013) 627-641.

21. S.Mirasgedis, Y.Sarafidis, E.Georgopoulou, D.P.Lalas, M.Moschovits, F.Karagiannis, D.Papakonstantinou, Energy 31(2006)208-227.

22. OID, 2017. Baromètre performance énergétique des bâtiments tertiaires 2017 .

23. T.Østergård, R.Jensen, S.Maagaard, App. En.211 (2018) 89-103.

24. M.Ranjan, V.K.Jain, Energy 24(1999)351-361

25. Z.Romani, A.Draoui, F.Allard, En.Build.102(2015)139-148.

26. SYPEMI, 2015. Guide des indicateurs environnementaux d'exploitation.

27. W.Tian, Build.Env, 92 (2015) 61-74.

28. E. Vorger, 2015. https://pastel.archivesouvertes.fr/tel-01144461

29. K.K.W.Wan, D.H.W.Li, J.C.Lam, Energy36 (3) (2011) 1404-1414.

30. K.-E. Westergren, H.Högberg, U.Norlén, En.Build. 29 (1999) 247-257.

31. Z.Yang, B. Becerik-Gerber, App.En. 149(2015) 415-431.

32. B.Yildiz, J.L. Bilbao, A.B.Sproul. Ren.Sust.En.Rev. 73 (2017) 1104-1122.

33. Y.R.Yoon, H.J.Moon, En.Build. 168 (2018) 215 224 